This article has been accepted for publication in Journal of the science of food and agriculture, published by Wiley.

The final authenticated version is available online at_10.1002/jsfa.9262

Terms of use see Wiley article sharing policy https://authorservices.wiley.com/asset/Article Sharing Guidelines.pdf for archived author accepted manuscripts (AAMs) of subscription articles. 


\title{
Enhancement of Istrian Malvasia wine aroma and hydroxycinnamates composition by hand and mechanical leaf removal
}

\author{
Running title: Enhancement of wine aroma and hydroxycinnamates composition by \\ leaf removal
}

\author{
Marijan Bubola, ${ }^{\mathrm{a}^{*}}$ Igor Lukić, ${ }^{\mathrm{a}}$ Sanja Radeka, ${ }^{\mathrm{a}}$ Paolo Sivilotti, ${ }^{\mathrm{b}}$ Kristina Grozić, ${ }^{\mathrm{a}}$ \\ Andreja Vanzo, ${ }^{\mathrm{c}}$ Dejan Bavčar ${ }^{\mathrm{c}}$ and Klemen Lisjak $^{\mathrm{c}}$
}

\author{
${ }^{a}$ Institute of Agriculture and Tourism, Karla Huguesa 8, 52440 Poreč, Croatia \\ ${ }^{\mathrm{b}}$ University of Udine, Department of Agricultural, Food, Environmental and Animal \\ Sciences, Via delle Scienze 206, 33100 Udine, Italy \\ ${ }^{c}$ Agricultural Institute of Slovenia, Hacquetova ulica 17, 1000 Ljubljana, Slovenija
}
*Correspondence to: Marijan Bubola, Institute of Agriculture and Tourism, Karla Huguesa 8, 52440 Poreč, Croatia. E-mail: marijan@iptpo.hr

\begin{abstract}
BACKGROUND: Leaf removal is a viticultural practice that promotes the biosynthesis of several important grape constituents by improving fruit zone microclimate. The purpose of this study was to assess the effects of hand and mechanical leaf removal, applied at pea-size stage of berry development, on fruit zone microclimate, volatile aroma compounds, hydroxycinnamates and sensory characteristics of Istrian Malvasia
\end{abstract}

This article has been accepted for publication and undergone full peer review but has not been through the copyediting, typesetting, pagination and proofreading process, which may lead to differences between this version and the Version of Record. Please cite this article as doi: 10.1002/jsfa.9262 
(Vitis vinifera L.) wines. Three different sunlight exposure conditions were applied by hand leaf removal (HLR), mechanical leaf removal (MLR) and untreated control (UC).

RESULTS: Both leaf removal treatments, and especially the more intense HLR, significantly increased the concentration of varietal thiol 3-sulfanylhexan-1-ol, monoterpenes, $\beta$-damascenone and esters. The higher concentration of these aromas contributed to the improvement of wine sensory quality, as expressed by more enhanced floral, fruity and tropical sensory attributes in leaf removal treatments. Hydroxycinnamates were increased only by HLR, a treatment with a greater degree of fruit exposure to sunlight than MLR.

CONCLUSION: Leaf removal applied at pea-size stage of berry development in a season characterized by abundant rainfall improve both the chemical composition and sensory quality of Istrian Malvasia wine, even when performed by machine, implying that this technique might be successfully applied in large-scale viticultural production.

Keywords: leaf removal; Vitis vinifera L.; varietal thiols; aroma compounds; hydroxycinnamates. 


\section{INTRODUCTION}

Leaf removal is a common grapevine canopy management practice adopted to remove leaves around clusters, with the aim to improve fruit zone microclimate and especially to increase sunlight exposure of grapes, temperature of berries and air circulation in the fruit zone. This technique has been widely studied in recent years due to its impact on grape and wine composition. ${ }^{1-5}$ Most research on leaf removal has been performed on red grapevine varieties due to its influence on phenolic composition of grapes and their resultant wines, ${ }^{6-10}$ and to a lower extent on white grapevine varieties due to the importance of fruit zone sunlight exposure on grape and wine aroma compounds, ${ }^{11-13}$ hydroxycinnamates ${ }^{1,5,14}$ and sensory quality of wines. ${ }^{15-17}$

As several enzymes involved in the biosynthesis of terpenoids and other aroma compounds in grapes were reported to have a light-dependent regulation, ${ }^{11,18}$ by improving fruit zone microclimate leaf removal promotes the formation of some aroma compounds biosynthesized in grape berries, like monoterpenes ${ }^{11,19}$ and $\mathrm{C}_{13^{-}}$ norisoprenoids, ${ }^{19,20}$ while the concentration of other compounds, like methoxypyrazines, may be reduced. ${ }^{2,13,21,22}$ Interestingly, there is evidence that leaf removal practice may also increase the amounts of particular yeast-derived aroma compounds in the produced wine, such as ethyl or acetate esters..$^{10,16,23,24}$

Varietal thiols 3-sulfanylhexan-1-ol (3SH), 3-sulfanylhexyl acetate (3SHA), 4-methyl4-sulfanylpentan-2-one (4MSP) are sulfur-containing aroma compounds, which strongly affect the sensory profile of some varietal wines, like Sauvignon blanc, giving them a so-called tropical character. ${ }^{25,26}$ However, there are only few studies dealing with the impact of leaf removal on the concentration of varietal thiols in wine ${ }^{13,16,17}$ and all of them were carried out on Sauvignon blanc variety. Leaf removal increased the 
concentration of 3SH and 3SHA in Sauvignon blanc wines, ${ }^{16,17}$ while no differences were observed between shaded and exposed clusters taken from the same vines. ${ }^{13}$

Istrian Malvasia (Vitis vinifera L.) is a grapevine variety from the north Adriatic area, mainly grown in Istria region of Croatia, ${ }^{27}$ Friuli region of Italy and in Primorska region of Slovenia. In the last two decades there were cases anecdotally reported by local wine experts that the aroma profile of particular Istrian Malvasia wines strongly resembled that typical of Sauvignon blanc, and even the adulteration of Istrian Malvasia by the addition the excessive quantities of Sauvignon blanc was suspected. Since the varietal thiols are typical key aroma compounds of Sauvignon blanc wine flavour, they were included in this study in order to investigate for the first time their occurrence in Istrian Malvasia wines, but also to assess their response to leaf removal on a variety other than Sauvignon blanc. Hand leaf removal is currently a standard practice used by Istrian Malvasia growers in the region, although the interest in mechanical leaf removal is increasing in the last years due to its ease to use on a large scale and the lack of available labor for performing manual operations.

Therefore, the purpose of this study was to assess the effects induced by leaf removal, applied at pea-size stage of berry development, on aroma compounds, hydroxycinnamates and sensory characteristics of Istrian Malvasia wines. In particular, the effects of hand and mechanical leaf removal, accounting for a different intensity of removed leaves, were compared to each other and to an untreated control.

\section{MATERIALS AND METHODS}

\section{Vineyard site, vine material and experimental setup}


The experiment was carried out in 2014 in a commercial, non-irrigated vineyard located near Koreniki (lat. $45^{\circ} 24^{\prime} \mathrm{N}$; long. $13^{\circ} 34^{\prime} \mathrm{E} ; 65 \mathrm{~m}$ asl), in Istria wine growing region, Croatia. Istrian Malvasia grapevines (clone VCR4) grafted on SO4 rootstock were planted in 1994 in a chromic luvisol soil. ${ }^{28}$ Vines were planted with a spacing of $1.0 \mathrm{~m}$ within row and $2.5 \mathrm{~m}$ between rows. Vines were trained to a vertically shoot-positioned, single-cane-pruned Guyot trellis. Vineyard rows were oriented north-south. Meteorological data were recorded by a Spectrum WD 1650 weather station (Spectrum Technologies, Aurora, IL) located in the vineyard.

Four adjacent rows were selected to build a randomized complete block design, with each row as a block. Within each row, three sections of three post spaces (15 vines per plot, $15 \mathrm{~m}$ row length) were tagged and randomly assigned to the following treatments: hand leaf removal (HLR), mechanical leaf removal (MLR) and untreated control (UC). Three post spaces at the beginning of each row were not included in the experiment and were used as buffer.

Both hand and mechanical leaf removal were carried out on 17 June 2014, 19 days after full bloom, at pea-size stage of berry development, which corresponds to grapevine growth stage 31 according to the modified E-L system. ${ }^{29}$ Leaves were removed in basal $50 \mathrm{~cm}$ of the canopy wall, a zone ranging from the base of the shoot to the node above the top cluster. HLR consisted of the manual removal of five leaves per primary shoot, or approximately $70 \%$ of leaves from primary shoot in basal $50 \mathrm{~cm}$ of the canopy wall. Leaves were uniformly removed throughout this zone in order to leave some leaves around clusters to act as a partial barrier to direct sunlight. MLR was performed with the tractor mounted roll-over defoliator (Model DS0, VBC Macchine Agricole, Colognola ai Colli, Italy). The height of the machine was set right above the basal wire 
so as to cover a shoot length that mimicked that of the hand treatment. Only the outer leaves were mechanically defoliated. It was visually assessed that approximately two to three leaves per primary shoot were removed in MLR treatment, or approximately $35 \%$ of leaves from primary shoot in basal $50 \mathrm{~cm}$ of the canopy wall, and no damage to clusters occurred following this treatment. In both HLR and MLR, leaves were removed from both sides of the row.

\section{Fruit zone microclimate}

The photosynthetic active radiation (PAR) and temperature were continuously monitored from leaf removal to harvest date at the cluster level inside the canopy at 15min intervals. PAR ( $\mu$ mol m $\mathrm{m}^{-2} \mathrm{~s}^{-1}$ ) was monitored using QSO-S PAR Photon Flux sensors (Decagon Devices, Pullman, WA) located in the fruit zone and placed vertically upward, while temperature was monitored using TMC6-HD temperature sensors (Onset, Cape Cod, MA) located inside grape clusters, in close contact with the berries. For both PAR and temperature measurements, eight sensors were used per treatment, two per each experimental plot.

On 1 September 2014, PAR availability in the fruit zone was determined between 11:00 and 12:30 h on cloudless conditions using a portable QSO-S PAR Photon Flux sensor (Decagon Devices, Pullman, WA), placed vertically upward near clusters on both sides of the canopy. One hundred clusters per replicate were used for PAR measurements, half of them on the east side of the canopy and the other half on the west side. Point quadrat analysis (PQA) was performed as described Smart and Robinson ${ }^{30}$ upon leaf 
removal and at harvest in order to determine canopy gaps and leaf layer number (LLN) in the fruit zone.

\section{Leaf area, yield components and Botrytis cinerea rot estimation}

Six representative shoots per replicate were collected at harvest and brought to the laboratory in plastic bags. Primary and lateral leaf area of each sample was assessed using a method based on the disc technique. ${ }^{30}$ All vines were harvested by hand on 16 September 2014. Yield and number of clusters per vine were recorded and average cluster weight calculated. Berry number per cluster was calculated from cluster and single berry weight, obtained by a sample of 200 berries. At harvest, 50 clusters per replicate were randomly collected and visually inspected for Botrytis cinerea rot incidence (percent of clusters with rot) and rot severity (percent of affected berries) by the EPPO Guidelines for the efficacy evaluation of fungicides. ${ }^{31}$

\section{Microvinifications}

Microvinifications were conducted separately for each experimental plot, leading to a total of 12 fermentations. At harvest date, approximately $35 \mathrm{~kg}$ of grapes obtained per treatment replication were de-stemmed, crushed and then pressed in a pneumatic press to 1.5 Bar. After the first pressing, grape marc was mixed and pressed once again the same way. After adding $50 \mathrm{mg} \mathrm{L}^{-1} \mathrm{SO}_{2}$ and pectolytic enzymes $\left(20 \mathrm{mg} \mathrm{L}^{-1}\right.$, Lallzyme C-Max, Lallemand, Montreal, Canada), juice was clarified at $8{ }^{\circ} \mathrm{C}$ overnight in $10 \mathrm{~L}$ glass bottles. After $24 \mathrm{~h}$ of settling, $4.5 \mathrm{~L}$ of clarified juice was racked to $5 \mathrm{~L}$ glass bottles, inoculated with yeast Saccharomyces cerevisiae VIN 13 Anchor (Oenobrands, 
Montpellier, France; $0.3 \mathrm{~g} \mathrm{~L}^{-1}$ ) and supplied with yeast nutrient Go-Ferm Protect (Lallemand, Montreal, Canada; $0.3 \mathrm{~g} \mathrm{~L}^{-1}$ ). Fermentations were carried out at $15{ }^{\circ} \mathrm{C}$. Three days after the beginning of fermentation $0.2 \mathrm{~g} \mathrm{~L}^{-1}$ of yeast nutrient Fermaid $\mathrm{E}$ (Lallemand, Montreal, Canada) was added. At the end of the fermentation wines were racked, $50 \mathrm{mg} \mathrm{L}^{-1} \mathrm{SO}_{2}$ was added, samples for the analysis of basic wine composition (alcohol, titratable acidity, $\mathrm{pH}$, total extract, residual sugar, dry extract and ash) were taken, and wines were stored at $15^{\circ} \mathrm{C}$ in $2 \mathrm{~L}$ glass bottles. Wine samples for the analysis of aroma compounds and hydroxycinnamates were stored at $-20^{\circ} \mathrm{C}$ upon analysis.

\section{Composition of grape juice, berries and wine}

Brix (soluble solids) in grape juice was determined using a HR200 digital refractometer (APT Instruments, Litchfield, IL), pH was determined using a MP220 pH-meter (Mettler Toledo, Germany), and titratable acidity (TA; expressed as $\mathrm{g} \mathrm{L}^{-1}$ tartaric acid equivalents) was measured by titration with $\mathrm{NaOH} 0.1 \mathrm{~N}$. Standard physico-chemical wine parameters were determined according to the methods of the International Organization of Vine and Wine. ${ }^{32}$

For the determination of precursors of varietal thiols, berries were sampled at the harvest date in the morning hours from both sides of the vine, with only one berry taken per cluster. Samples were immediately frozen in liquid nitrogen in the field and stored at $-80^{\circ} \mathrm{C}$ prior to analysis. Four samples were taken per treatment, one from each vineyard row, with 50 berries randomly selected per replicate. The UHPLC-MS/MS analysis of precursors of varietal thiols 3-S-glutathionylhexan-1-ol (G3SH), 3-Scysteinylhexan-1-ol (Cys3SH), 4-S-glutathionyl-4-methylpentan-2-one (G4MSP) and 4- 
S-cysteinyl-4-methylpentan-2-one (Cys4MSP) in berries was carried out using the method described in details by Vanzo et al. ${ }^{33}$ by a UHPLC-MS/MS. Briefly, $10 \mathrm{~g}$ aliquot of pulverized frozen grapes was rapidly transferred into cold, deoxygenated methanol (1:4 w/v), spiked with deuterium labeled internal standards (Cys-4MSP-d6 and G-4MSP- $d 10)$, vortexed, extracted and centrifuged. The extract $(200 \mu \mathrm{L})$ was filtered through a $0.22 \mu \mathrm{m}$ PVDF Millipore filter and directly injected onto UHPLCMS/MS. When the thiol precursors were below analytical limits for evaluation by direct injection, grape extracts were concentrated and purified by the use of ion-exchange resin and subsequently a hydrophobic cartridge. Thiol precursors after purification procedure were quantified considering recoveries of deuterated internal standards.

Determination of varietal thiols 4MSP, 3SH and 3SHA in wine was performed using a modified method of Tominaga et al., ${ }^{26}$ described by Šuklje et $a l .{ }^{34}$ by GC-MS (Agilent Technologies) equipped with MPS 2 automatic sampler (Gerstel, Germany). The linearity of the detector response for thiols was verified in thiol standard solutions. Ten concentration levels (up to $99.8 \mathrm{ng} / \mathrm{L}, 1997 \mathrm{ng} / \mathrm{L}$ and $3994.3 \mathrm{ng} / \mathrm{L}$ for 4MSP, 3SHA and 3SH respectively) were injected in 6 repetitions for each level. Linearity was determined using the F-test and multiple linear regressions and was 0.89799, 0.99904, and 0.99858 for $4 \mathrm{MSP}, 3 \mathrm{SHA}$ and $3 \mathrm{SH}$ respectively. Limits of quantification (LOQ) were calculated by considering signal to noise $\mathrm{S} / \mathrm{N}=10$. LOQ were $2 \mathrm{ng} / \mathrm{L}, 5 \mathrm{ng} / \mathrm{L}$ and $60 \mathrm{ng} / \mathrm{L}$ for $4 \mathrm{MSP}, 3 \mathrm{SHA}$ and $3 \mathrm{SH}$ respectively. To assess the repeatability of the method, white wine samples were sequentially injected four days in three repetitions $(\mathrm{N}$ $=12)$, and the relative standard deviations of repeatability (RSDr) were 7.9\%, $13.4 \%$ and $24.9 \%$ for 4MSP, 3SHA and 3SH respectively. 
Free volatile aroma compounds in wine were isolated using headspace solid-phase microextraction (HS-SPME) according to the modified method proposed by NoguerolPato et al., ${ }^{35}$ and analyzed by gas chromatography/mass spectrometry (GC/MS).

Four milliliters of a four-fold diluted sample were placed in a $10 \mathrm{~mL}$ glass vial. Ammonium sulphate $(1 \mathrm{~g})$ and $50 \mu \mathrm{L}$ of an internal standards solution (2-octanol $(0.84$ $\mathrm{mg} / \mathrm{L}$ of wine, for monoterpenes, C13-norisoprenoids, and alcohols); methyl nonanoate (0.82 $\mathrm{mg} / \mathrm{L}$, for esters), and heptanoic acid $(2.57 \mathrm{mg} / \mathrm{L}$, for fatty acids) were added. After 15-min preconditioning at $40^{\circ} \mathrm{C}$, microextraction using a DVB-CAR-PDMS fibre (Supelco, Bellafonte, PA, USA) lasted for $40 \mathrm{~min}$ at $40{ }^{\circ} \mathrm{C}$ with stirring (800 rpm). For desorption, the fibre was inserted into a GC/MS injector port at $248{ }^{\circ} \mathrm{C}$ for $5 \mathrm{~min}(3 \mathrm{~min}$ splitless mode).

Identification of aromas was performed using a Varian 3900 GC coupled with a Varian Saturn 2100T ion trap mass spectrometer (Varian Inc., Harbour City, CA). The column was a $60 \mathrm{~m} \times 0.25 \mathrm{~mm}$ i.d. $\times 0.25 \mu \mathrm{m}$ d.f. Rtx-WAX (Restek, Belafonte, PA). Initial oven temperature was $40{ }^{\circ} \mathrm{C}$, increased at $2{ }^{\circ} \mathrm{C} / \min$ to $240{ }^{\circ} \mathrm{C}$, and then kept at $240{ }^{\circ} \mathrm{C}$ for $10 \mathrm{~min}$. The carrier gas was helium $(1 \mathrm{~mL} / \mathrm{min})$. Mass spectra were acquired in EI mode $(70 \mathrm{eV})$, at $30-450 \mathrm{~m} / \mathrm{z}$. Identification was performed by comparing retention times and mass spectra with those of pure standards, and with mass spectra from NIST05 library. Linear retention indices (relative to $n$-alkanes from $\mathrm{C}_{10}$ to $\mathrm{C}_{28}$ ) were calculated. Standard calibration curves were constructed. The suitability of the method was verified by testing the linearity, limits of quantification, and repeatability (Supporting Information, Table S1).

Hydroxycinnamic acids and their esters in wine were determined by HPLC-DAD (Agilent Technologies 1100, Palo Alto, USA) as described previously. ${ }^{36,37}$ The method 
was developed for monitoring cis- and trans-caftaric acid, coutaric acid, and fertaric acid, respectively, together with caffeic, $p$-coumaric, and ferulic acid and also a glutathione derivative of caftaric acid (GRP).

\section{Quantitative descriptive sensory analysis of wines}

Quantitative descriptive sensory analysis was performed by a panel of six trained certified panelists (four male, two female, age between 30 and 50), highly experienced in Istrian Malvasia wine sensory analysis. Wine samples stored at $11^{\circ} \mathrm{C}$ were served in standard wine tasting glasses at room temperature $\left(20{ }^{\circ} \mathrm{C}\right)$ under white light. Tasters were seated in separate purpose-made booths, and the environment was free of interference in terms of noise, visual stimulation and ambient odor. Qualitative (selection of main descriptors and standardization of vocabulary) and quantitative (intensity of perception) criteria of the panelists were attuned by tasting representative samples of Istrian Malvasia wine through several preliminary training sessions and at the beginning of the sensory analysis. Samples were served to tasters according to randomized three-digit number for identification. The tasters used a 10-point structured scale to rate aroma or taste intensity of each descriptor $(0=$ descriptor not perceptible, $10=$ descriptor strongly perceptible).

\section{Statistical analysis}

The experiment consisted of one factor with four replications. A one-way analysis of variance was computed using mixed model procedure (SAS Institute, Cary, NC), with investigated factor considered as fixed effect and replication as random effect. When 
differences among treatments were significant, Fisher's least significant difference test at $p \leq 0.05$ was used to separate the means. Line scatters and radar charts were constructed using SigmaPlot 13 (Systat Software GmbH, Erkrath, Germany).

\section{RESULTS}

\section{Meteorological conditions}

Growing degree days calculated on a base temperature of $10^{\circ} \mathrm{C}$ reached $1667{ }^{\circ} \mathrm{C}$ in the period from 1 April to 30 September and were the highest in June, July and August (Supporting Information, Table S2). Season 2014 was characterized by abundant rainfall during the summer months, with peaks in July $(163 \mathrm{~mm})$ and September (137 $\mathrm{mm}$ ), and with a total of $565 \mathrm{~mm}$ from 1 April to 30 September. According to the data provided by the Meteorological and Hydrological Service of Croatia, the 30 years mean (1981-2010) for the neighboring Poreč was $418 \mathrm{~mm}$ of rainfall for the same period, while the month with the highest mean rainfall was September with $95 \mathrm{~mm}$ and the month with the lowest mean rainfall was July with $43 \mathrm{~mm}$.

\section{Fruit zone microclimate}

Photosynthetic active radiation (PAR) inside the fruit zone measured throughout the period from leaf removal date to harvest was the highest in HLR and the lowest in UC throughout the day (Figure 1A). All treatments had two peaks of PAR during the day, one in the morning, from 7 a.m. to 12. p.m. and other in the afternoon, from 3 p.m. to 8 p.m. Two weeks before harvest, PAR determined near clusters was approximately two and four times higher for MLR and HLR as compared to UC, respectively (Table 1). 
Similar pattern to PAR dynamics during the day was observed also for temperature of clusters. Higher values were observed in both leaf removal treatments than in UC during the morning and in the afternoon, when temperature was $1.5^{\circ} \mathrm{C}$ higher in the HLR than in the UC (Figure 1B). During the night (from 7:30 p.m. to 7:00 a.m.), slightly cooler temperatures in both leaf removal treatments $\left(0.2\right.$ to $0.3{ }^{\circ} \mathrm{C}$ lower in comparison to UC) were observed.

Both upon leaf removal and at harvest UC was characterized by the lowest \% canopy gaps and the highest leaf layer number (LLN), while HLR had the most open fruit zone (Table 1).

\section{Leaf area, yield components and Botrytis cinerea cluster rot}

At harvest, primary shoot leaf area and total leaf area per vine was the highest in UC and the lowest in HLR (Table 1), while no significant differences in lateral shoot leaf area were obtained among treatments. Yield components and leaf area/yield ratio did not differ significantly among treatments, with the exception of berry weight, which was $4 \%$ lower in HLR in comparison to UC (Table 2). Botrytis cinerea rot incidence and severity were the highest in UC and the lowest in HLR.

\section{Basic composition of grape juice and wine}

Both leaf removal treatments had higher Brix and lower TA in grape juice in comparison to UC (Table 3). The alcohol content and TA in wine followed the same trends as observed for Brix and TA in grape juice; both leaf removal treatments induced the increase of the former and a decrease of the latter, although the difference in wine 
TA between MLR and UC was not significant (Table 3). The concentration of total dry extract, residual sugar and ash in wine did not differ among treatments.

\section{Precursors of varietal thiols in berries}

No significant differences among treatments were found for the content of cysteinylated and glutathionylated precursors of 4MSP and 3SH in berries (Table 4), although higher concentrations of all varietal thiols precursors were observed in the two leaf removal treatments as compared to UC.

\section{Aroma compounds in wine}

Leaf removal treatments applied in this study affected the concentration of varietal thiols in wine (Table 5). In comparison to UC, the concentration of 4MSP was $30 \%$ and $38 \%$ lower in MLR and HLR, while the concentration of $3 \mathrm{SH}$ was $27 \%$ and $34 \%$ higher in the same treatments, respectively. On the other hand, 3SHA was not detected in any of the wines. Several monoterpenes in wine were affected by leaf removal treatments (Table 5); concentrations of nerol and geraniol increased by both leaf removal treatments in comparison to UC, linalool was higher in HLR than in UC, while citronellol was the highest in MLR. Only $\alpha$-terpineol was not affected by leaf removal. The concentration of a $\mathrm{C}_{13}$-norisoprenoid $\beta$-damascenone in wine was increased by both leaf removal treatments. No significant impact of investigated treatments was observed for 1-hexanol and 2-phenylethyl alcohol. The concentration of most ethyl esters increased with leaf removal and especially by HLR, with the exception of ethyl isobutyrate. Both leaf removal treatments increased the concentration of acetate esters 
isobutyl acetate and isoamyl acetate in comparison to UC, while for 2-phenylethyl acetate the increase was not significant. Among the fatty acids, hexanoic acid was increased by both leaf removal treatments, while no significant effect was determined for octanoic and decanoic acid.

\section{Hydroxycinnamates in wine}

The concentration of hydroxycinnamates in wine was increased only by HLR (Table 5); this effect was the most significant in the case of trans-caftaric acid (+53\% vs UC and $+35 \%$ vs MLR), following by cis-caftaric acid (+44\% vs UC), trans-fertaric acid (+24\% vs UC and $+13 \%$ vs MLR) and for total hydroxycinnamates in wine ( $+26 \%$ vs UC and $+18 \%$ vs MLR).

\section{Wine sensory evaluation}

Floral, fruity and tropical sensory attributes were enhanced in leaf removal treatments in comparison to UC, while vegetative/herbaceous notes were more expressed in UC (Figure 2). Acidity was more pronounced in UC, while leaf removal treatments, especially HLR, resulted in higher values of wine body. Aftertaste quality and intensity were graded with the highest values in HLR and with the lowest in UC, and a similar pattern was noted for wine overall quality.

\section{DISCUSSION}

\section{Fruit zone microclimate}


Due to different leaf removal approaches in MLR and HLR, the three investigated treatments represented three different fruit exposure conditions, which significantly differed in percent of canopy gaps and leaf layer number (LLN) in the fruit zone throughout the growing season (Table 1). From leaf removal date to harvest canopy gaps decreased and LLN increased in all treatments because of the regrowth of lateral shoots in the fruit zone.

The dynamics of fruit zone PAR during the day in this experiment, where vineyard rows were oriented north-south, indicates that the greatest fruit exposure to sunlight was obtained during the morning and the afternoon (Figure 1A), a trend observed also by Feng et al. ${ }^{38}$ During the morning and afternoon hours particularly high value of incident PAR was determined in HLR, and to a lesser extent in MLR. Different level of sunlight exposure was reflected also in different cluster temperatures among treatments (Figure 1B). Around midday PAR was lower in all treatments, because the leaves positioned on the upper part of the canopy reduced sunlight penetration in the fruit zone, and at that time almost the same cluster temperatures were recorded in all treatments. In our study cluster temperature during the night was slightly lower in both leaf removal treatments

than in UC, a trend also observed in previous research. ${ }^{37,39}$ This may be explained by a better air circulation in the fruit zone of leaf removal treatments, which imposed faster cooling of clusters.

\section{Yield components and cluster health}

The investigated treatments did not significantly affect yield components nor the leaf area/yield ratio, with the exception of berry mass, which was lower in HLR than in UC 
(Table 2), as berries in the shade tend to be heavier than those better exposed to sunlight. ${ }^{39}$ No impact of leaf removal on yield was observed also in other studies where leaf removal was performed at berries pea-size stage or later. ${ }^{15,38}$ Owing to a more open canopy, MLR, and especially HLR, effectively reduced Botrytis cinerea incidence and severity compared to UC, a trend observed also by other authors., ${ }^{2,9,21,22,40}$ Istrian Malvasia is not susceptible on Botrytis cinerea $^{41}$ and the values of Botrytis cinerea incidence and severity obtained in this study are considered rather high for cultivar and region, as they are a consequence of the growing season with unusually high rainfall.

\section{Basic composition of grape juice and wine}

Since the leaf area/yield ratio was not limiting to produce maximum level of Brix in berries according to Kliewer and Dokoozlian, ${ }^{42}$ higher Brix and also lower TA in both leaf removal treatments than in UC was most probably a consequence of different exposure of clusters to sunlight among treatments. Several studies report that sugar accumulation is greater for light-exposed fruit than for non-exposed fruit, ${ }^{1,4,9,13,39,40}$ while the concentration of TA is higher in shaded fruit, ${ }^{13,40}$ although there are cases where leaf removal did not impact basic berry composition. ${ }^{23,38,43}$

\section{Precursors of varietal thiols in berries}

In our study the increase of cysteinylated and glutathionylated precursors of 4MSP and 3SH in berries of MLR and HLR was not significant as compared to UC (Table 4), while Sivilotti et $a .^{43}$ reported a significant increase of G4MSP and G3SH in grapes caused by leaf removal. Kobayashi et al. ${ }^{44}$ suggested that environmental stress, like 
increased UV radiation of grapes, enhances the biosynthesis of precursors of varietal thiols $\mathrm{G} 3 \mathrm{SH}$ and $\mathrm{Cys} 3 \mathrm{SH}$ in grapevine berries.

Botrytis cinerea infection of berries could increase the amount of Cys3SH and G3SH in grapes. ${ }^{44}$ In our study, despite the higher Botrytis cinerea incidence and severity in UC grapes than in leaf removal treatments, the lowest concentrations of all precursors of varietal thiols were observed in UC. The reason for this outcome could be in grape sampling, as in our study only healthy berries were sampled for grape analyses.

\section{Aroma compounds in wine}

Although the concentrations of precursors of varietal thiols in berries did not significantly differ among treatments, both leaf removal treatments increased $3 \mathrm{SH}$ in wines (Table 5), while 4MSP was lower in wines from same treatments as compared to UC. Our results concerning $3 \mathrm{SH}$ are in accordance to those found in some other studies on leaf removal. ${ }^{16,17}$ On the other hand, Martin et al. ${ }^{13}$ obtained no differences in concentrations of $3 \mathrm{SH}$ in wine between shaded and exposed clusters taken from the same vines. As the mechanism of the release of thiols from their precursors by yeasts during alcoholic fermentation is complex and not completely known, ${ }^{25}$ possibly some other compounds or parameters which were not investigated in our study interfered to lower the conversion rate of 4MSP precursors in the corresponding thiol during fermentation. To our knowledge there are no previous reports about the effect of leaf removal on 4MSP in wine.

Interestingly, UC treatment, which had the highest Botrytis cinerea incidence and severity on grapes, also had the lowest concentration of $3 \mathrm{SH}$ in the resulting wines. This 
is in contrast with the finding that $3 \mathrm{SH}$ concentration in wine was considerably higher when Botrytis cinerea was developed on grapes, ${ }^{45}$ and it suggests that fruit exposure rather than Botrytis cinerea infestation had greater impact on 3SH in Istrian Malvasia wine in our study. Another possible reason for the enhancement of $3 \mathrm{SH}$ in wines of leaf removal treatments may be the more advanced maturity stage concerning Brix for HLR and MLR as compared to UC, as discussed above for varietal thiols precursors in grapes. Although the concentrations of 3SH and 4MSP in Istrian Malvasia wines were slightly lower than those found in Sauvignon blanc wines in other studies, ${ }^{13,16,17}$ both varietal thiols were above the sensory perception threshold, ${ }^{25,26}$ indicating that Istrian Malvasia's tropical odors reminiscent of Sauvignon blanc most probably originated from varietal thiols.

Greater berry exposure to sunlight in leaf removal treatments increased the concentration of four monoterpenes out of five determined in the wines (linalool, citronellol, nerol and geraniol), as compared to the more shaded UC (Table 5), and similar results were found in other recent studies. ${ }^{4,7}$ These results were expected, as light promotes the expression of monoterpene metabolic genes in berries ${ }^{11}$ and the differences in the concentration of monoterpenes in wines obtained by the investigated treatments most probably resulted from a variation of their glycosidic precursors biosynthesis in berries. Monoterpenes are especially increased in response to leaf removal in the later stages of berry development, ${ }^{19}$ leading to the largest differences between shaded and exposed berries at the time of harvest. ${ }^{20}$ Concerning the biological role of monoterpenes in berries, it is supposed that they are involved in the protection of berry tissue from UV-B radiation and other abiotic and biotic stresses. ${ }^{19,46,47}$ Although UV-B radiation was not specifically measured in our study, it can be inferred that it was 
greater in leaf removal treatments than in UC, considering the differences in PAR, canopy gaps and LLN in the fruit zone among treatments, and that it likely stimulated the biosynthesis of monoterpenes. As the concentration of monoterpenes in berries increases during maturation, while Brix is increasing, ${ }^{20,48}$ the higher concentrations of monoterpenes in leaf removal treatments in our study were, at least partly, also a consequence of the more advanced maturation stage regarding Brix in both leaf removal treatments as compared to UC.

Similarly to monoterpenes, the concentration of $\beta$-damascenone in wines was positively affected by both leaf removal treatments (Table 5), since $\beta$-damascenone concentration in berries is usually enhanced by greater fruit exposure to sunlight. ${ }^{20,48}$ Higher concentration of $\beta$-damascenone in wine following leaf removal was found also by Feng et al., ${ }^{7}$ where this practice was imposed at the same berry stage as in our study. Conversely, no significant difference in $\beta$-damascenone concentration between shaded and exposed treatment was found by Song et al., ${ }^{4}$ where leaf removal was imposed at a later stage of berry development, presumably close to the beginning of veraison.

In studies where the exposure of clusters to sunlight is modulated, it is usually difficult to determine if light or temperature had the prevailing effect on the composition of grapes and the resultant and wines. However, we hypothesize that in our study the effect of light dominated over the effect of temperature in the enhancement of monoterpenes, $\beta$-damascenone and varietal thiols in wine, as large variation in PAR inside the fruit zone was observed among treatments throughout the day (Figure 1A and Table 1). In contrast, differences in the temperature of clusters among treatments were moderate and expressed only during few morning and afternoon hours (Figure 1B). If the temperature sensors would be located in the fruit zone instead inside the clusters, most probably very 
similar temperature trends would be obtained, as air circulation with its cooling effect may alleviate the warming effect induced by sunlight, as observed also by Šuklje et al. ${ }^{37}$

Although present in grapes, $\mathrm{C}_{6}$ alcohol 1-hexanol is a volatile compound mainly formed during pre-fermentation steps, and it can impart green and herbaceous aromas in wine. Leaf removal did not exhibit a significant effect on 1-hexanol, although slightly higher concentrations were observed in both leaf removal treatments (Table 5). Joubert et al. ${ }^{19}$ obtained higher levels of $\mathrm{C}_{6}$-compounds in berries grown in high light microclimate than in low light microclimate, and the authors speculated that this trend indicates a role of UVB radiation in their regulation and/or metabolism.

Despite a tendency of higher concentration in leaf removal treatments, 2-phenylethyl alcohol did not differ among treatments in our study (Table 5). This is in agreement with most other studies, where no effect of leaf removal on higher alcohols in wine was obtained, ${ }^{4,7,17,24}$ although in some studies higher concentrations were reported for leaf removal treatments. ${ }^{10,23}$

Esters are important contributors to wine aroma with odors generally described as fruity and floral. Interestingly, leaf removal in our study had a large effect on ethyl esters (Table 5), compounds which are generated by yeast metabolism during fermentation, implying that ethyl esters in wine are affected also by fruit exposure level. The increase of some or most ethyl esters in wine following leaf removal was obtained in several studies. ${ }^{10,16,23,24}$ As opposed to what could be expected from these results, amino acids as precursors for the formation of ethyl esters by yeasts during fermentation are negatively affected by leaf removal and retaining more leaves in the fruiting zone promotes their accumulation in berries. ${ }^{12,17}$ These contrasting results indicate that other factors connected with leaf removal, more than the concentration of amino acids in 
grape juice, affect the concentration of ethyl esters in wine. Šuklje et al. ${ }^{16}$ hypothesized that lower UV radiation inhibits polyunsaturated fatty acids (PUFAs) degradation in grapes, which results in the repression of genes involved in yeast activity and synthesis of acetates. The same authors assumed that the higher concentration of PUFAs negatively affects the production of ethyl esters, since PUFAs were shown to be more favorable substrates for yeasts than medium-chain acids, which consequently lowers the rate of synthesis of medium-chain ethyl esters. Similarly to ethyl esters, acetate esters isobutyl acetate and isoamyl acetate were also positively affected by both leaf removal treatments, which was generally in line with previous studies. ${ }^{10,23,24}$

From the fatty acids examined, only hexanoic acid was significantly increased by leaf removal treatments, although octanoic and decanoic acids had a tendency to be higher in wines obtained from more exposed grapes, and especially from HLR (Table 5). The increase in fatty acids was reported also in other studies, ${ }^{10,23,24}$ although in some cases no effect, ${ }^{7,16}$ or even lower concentrations were obtained by leaf removal. ${ }^{4}$

Inter-seasonal variation in weather conditions may influence the effects induced by leaf removal treatments. ${ }^{23,49}$ Our study was performed during a season which was characterized by abundant rainfall during the summer months and in these conditions leaf removal is of especial importance in terms of the increase of sunlight exposure of grapes, temperature of berries and air circulation in the fruit zone. Similarly, in other studies the highest effect of leaf removal on wine volatile composition ${ }^{23}$ and stilbenes ${ }^{49}$ was exhibited under cool and rainy meteorological conditions.

\section{Hydroxycinnamates in wine}


In our study leaf removal had a consistent impact on hydroxycinnamates only in the case of the most exposed fruit obtained by HLR, where the concentrations of transcaftaric, cis-caftaric, trans-fertaric acid and total hydroxycinnamates in wine were significantly higher compared to UC (Table 5). Almost no response on hydroxycinnamates was obtained by intermediately exposed MLR treatment, where only $p$-coumaric acid was increased compared to UC. Although several studies report no impact or very mild impact of leaf removal on wine hydroxycinnamates, ${ }^{5,14,37}$ Diago et al. ${ }^{1}$ reported higher values of most individual and total hydroxycinnamates in wine as a result of leaf removal. It should be noted here that as much as eight leaves per shoot were removed pre-bloom or at fruit set in the latter study, indicating that the increase of hydroxycinnamates in wine is possible only after higher degree of fruit exposure to sunlight. Similarly as indicated for specific aroma compounds, we assume that the effect of light dominated over the effect of temperature in the enhancement of hydroxycinnamates, based on the striking differences in PAR values between HLR and the other two treatments.

\section{Wine sensory evaluation}

Wines from the leaf removal treatments had more enhanced floral, fruity and tropical sensory attributes (Figure 2). The highest values were obtained by HLR, a treatment with the greatest fruit exposure to sunlight. It is probable that such differences among treatments derived from individual as well as cumulative contribution of particular volatile compounds, which are known to be carriers of floral, fruity and tropical odors and were found in concentrations notably higher than the corresponding odor perception

thresholds (OPT), such as 3SH and 4MSP (OPTs: 60 and $0.8 \mathrm{ng} / \mathrm{L}^{25}$ ), $\beta$-damascenone 
(OPT: $0.05 \mu \mathrm{g} / \mathrm{L}^{50}$ ), and fermentation esters (ethyl butyrate, OPT: $20 \mu \mathrm{g} / \mathrm{L},{ }^{50}$ ethyl 3methylbutyrate, OPT: $3 \mu \mathrm{g} / \mathrm{L},{ }^{51}$ ethyl hexanoate, OPT: $14 \mu \mathrm{g} / \mathrm{L},{ }^{51}$ ethyl octanoate, OPT: $5 \mu \mathrm{g} / \mathrm{L},{ }^{51}$ isoamyl acetate, OPT: $30 \mu \mathrm{g} / \mathrm{L}^{50}$ and 2-phenylethyl acetate, OPT: $250 \mu \mathrm{g} / \mathrm{L}^{50}$ ). In fact, their concentrations were mostly positively correlated with the intensity of the mentioned sensory attributes and were higher in wines from leaf removal treatments (Table 5). On the other hand, UC wine was characterized by a greater expression of vegetative/herbaceous notes, which may be an indirect consequence of the lower expression of floral and fruity attributes. Several leaf removal studies conducted on Sauvignon blanc variety obtained similar results; leaf removal increased the perceived

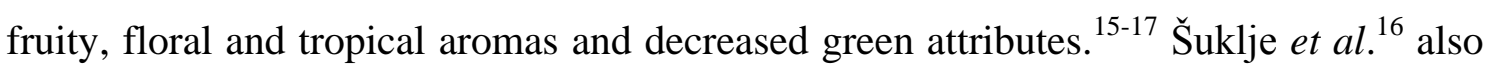
explained such outcome on the basis of higher concentrations of 3SH and esters, while Benkwitz et $a l .{ }^{52}$ demonstrated that not only varietal thiols, but also esters can be directly responsible for the tropical aroma perception in wine.

The concentrations of monoterpenes were generally below their OPT values. ${ }^{50}$ Monoterpenes are known to act synergistically and their cumulative effects might impact sensorial characteristics of wine, ${ }^{52}$ as they may have lower OPTs in the presence of other terpene compounds than in isolation. ${ }^{53}$ For this reasons, the possibility that they also contributed to the higher intensities of floral and fruity nuances in leaf removal treatment wines should not be neglected.

Enhanced taste attributes of MLR and especially HLR with respect to UC treatment, such as body and aftertaste, coincided reasonably with the increased concentrations of hydroxycinnamates, but also with increased alcohol content. 


\section{CONCLUSIONS}

The results of this study demonstrated that by regulating the intensity of leaf removal in a season characterized by abundant rainfall, many important chemical and sensory characteristics of Istrian Malvasia wine can be managed and improved. Leaf removal treatments, and especially the more intense HLR, significantly increased the concentration of $3 \mathrm{SH}$, monoterpenes, $\beta$-damascenone and esters, which directly reflected on the improvement of wine sensory quality. More intense positive odor notes, such as fruity, floral and tropical, as well as better aftertaste and overall quality, characterized wines obtained by leaf removal treatments. Although wine quality was enhanced to a larger extent when leaf removal was performed manually, the treatment by a tractor mounted roll-over defoliator also had a significant positive impact, which implies the possibility to successfully apply such canopy management practice on a large scale viticultural production. The noted positive relation between the level of fruit exposure to sunlight and the desirable compositional and sensory changes point out to a broad array of possibilities for obtaining Istrian Malvasia wine, but also wines from other varieties, with diverse ultimate composition as a function of the intensity of leaf removal. Besides that, the results of this study have put Istrian Malvasia in the group of only few grape varieties in the world which were confirmed to contain relevant amounts of varietal thiols in wine.

\section{ACKNOWLEDGEMENTS}

This research was partially funded by the Operational Program Slovenia-Croatia 20072013 IPA CBC under the project Malvasia TourIstra, by the Croatian Science 
Foundation under the project UIP-2014-09-1194 and by Slovenian Research Agency (research program No. P4-0133). We would like to thank Moreno Coronica for the use of his commercial vineyard, Dario Novacco for providing the tractor mounted defoliator and to dr. Helena Baša Česnik and dr. Špela Velikonja Bolta for their analytical assistance.

\section{SUPPORTING INFORMATION}

Supporting information may be found in the online version of this article.

\section{REFERENCES}

1. Diago MP, Ayestarán B, Guadalupe Z, Garrido Á and Tardaguila J, Phenolic composition of Tempranillo wines following early defoliation of the vines. $J$ Sci Food Agric 92:925-934 (2012).

2. Mosetti D, Herrera JC, Sabbatini P, Green A, Alberti G, Peterlunger E, Lisjak K and Castellarin SD, Impact of leaf removal after berry set on fruit composition and bunch rot in 'Sauvignon blanc'. Vitis, 55:57-64 (2016).

3. Rescic I, Mikulic-Petkovsek M and Rusjan D, The impact of canopy managements on grape and wine composition of cv. 'Istrian Malvasia' (Vitis vinifera L.). J Sci Food Agric 96: 4724-4735 (2016).

4. Song JQ, Smart R, Wang H, Dambergs B, Sparrow A and Qian MC, Effect of grape bunch sunlight exposure and UV radiation on phenolics and volatile composition of Vitis vinifera L. cv. Pinot noir wine. Food Chem 173:424-431 (2015). 
5. Sternad Lemut M, Sivilotti P, Franceschi P, Wehrens R and Vrhovsek U, Use of metabolic profiling to study grape skin polyphenol behavior as a result of canopy microclimate manipulation in a 'Pinot noir' vineyard. J Agric Food Chem 61:89768986 (2013).

6. Bubola M, Sivilotti P, Janjanin D and Poni S, Early leaf removal has a larger effect than cluster thinning on grape phenolic composition in cv. Teran. Am J Enol Vitic 68:234-242 (2017).

7. Feng H, Skinkis PA and Qian MC, Pinot noir wine volatile and anthocyanin composition under different levels of vine fruit zone leaf removal. Food Chem 214:736-744 (2017)

8. Osrečak M, Karoglan M and Kozina B, Influence of leaf removal and reflective mulch on phenolic composition and antioxidant activity of Merlot, Teran and Plavac mali wines (Vitis vinifera L.). Sci Hortic 209:261-269 (2016).

9. Palliotti A, Gardi T, Berrios JG, Civardi S and Poni S, Early source limitation as a tool for yield control and wine quality improvement in a high-yielding red Vitis vinifera L. cultivar. Sci Hortic 145:10-16 (2012).

10. Verzera A, Tripodi G, Dima G, Condurso C, Scacco A, Cincotta F, Giglio DML, Santangelo $\mathrm{T}$ and Sparacio A, Leaf removal and wine composition of Vitis vinifera L. cv. Nero d'Avola: the volatile aroma constituents. J Sci Food Agric 96:150-159 (2016).

11. Friedel M, Frotscher J, Nitsch M, Hofmann M, Bogs J, Stoll M and Dietrich H, Light promotes expression of monoterpene and flavonol metabolic genes and enhances flavour of winegrape berries (Vitis vinifera L. cv. Riesling). Aust J Grape Wine Res 22:409-421 (2016). 
12. Gregan SM, Wargent JJ, Liu L, Shinkle J, Hofmann R, Winefield C, Trought M and Jordan B, Effects of solar ultraviolet radiation and canopy manipulation on the biochemical composition of Sauvignon blanc grapes. Aust J Grape Wine Res 18:227-238 (2012).

13. Martin D, Grose C, Fedrizzi B, Stuart L, Albright A and McLachlan A, Grape cluster microclimate influences the aroma composition of Sauvignon blanc wine. Food Chem 210:640-647 (2016).

14. Bubola M, Peršurić Đ, Kovačević Ganić K, Karoglan M and Kozina B, Effects of fruit zone leaf removal on the concentrations of phenolic and organic acids in Istrian Malvasia grape juice and wine. Food Technol Biotechnol 50:159-166 (2012).

15. Coniberti A, Ferrari V, Dellacassa E, Boido E, Carrau F, Gepp V and Disegna E, Kaolin over sun-exposed fruit affects berry temperature, must composition and wine sensory attributes of Sauvignon blanc. Eur J Agron 50:75-81 (2013).

16. Šuklje K, Antalick G, Coetzee Z, Schmidtke LM, Baša Česnik H, Brandt J, du Toit WJ, Lisjak K and Deloire A, Effect of leaf removal and ultraviolet radiation on the composition and sensory perception of Vitis vinifera L. cv. Sauvignon Blanc wine. Aust J Grape Wine Res 20:223-233 (2014).

17. Šuklje K, Antalick G, Buica A, Langlois J, Coetzee ZA, Gouot J, Schmidtke LM and Deloire A, Clonal differences and impact of defoliation on Sauvignon blanc (Vitis vinifera L.) wines: a chemical and sensory investigation. J Sci Food Agric 96:915-926 (2016).

18. Singh B and Sharma RA, Plant terpenes: defence responses, phylogenetic analysis, regulation and clinical applications. 3 Biotech 5:129-151 (2015). 
19. Joubert C, Young PR, Eyéghé-Bickong HA and Vivier MA, Field-grown grapevine berries use carotenoids and the associated xanthophyll cycles to acclimate to UV exposure differentially in high and low light (shade) conditions. Front Plant Sci 7:786 (2016).

20. Young PR, Eyeghe-Bickong HA, du Plessis K, Alexandersson E, Jacobson DA, Coetzee Z, Deloire A and Vivier MA, Grapevine plasticity in response to an altered microclimate: Sauvignon blanc modulates specific metabolites in response to increased berry exposure. Plant Physiol 170:1235-1254 (2016).

21. Ferrari V, Disegna E, Dellacassa E and Coniberti A, Influence of timing and intensity of fruit zone leaf removal and kaolin applications on bunch rot control and quality improvement of Sauvignon blanc grapes, and wines, in a temperate humid climate. Sci Hortic 223:62-71 (2017).

22. Sivilotti P, Herrera JC, Lisjak K, Baša Česnik H, Sabbatini P, Peterlunger E and Castellarin SD, Impact of leaf removal, applied before and after flowering, on anthocyanin, tannin, and methoxypyrazine concentrations in 'Merlot' (Vitis vinifera L.) grapes and wines. J Agric Food Chem 64:4487-4496 (2016).

23. Moreno D, Valdés E, Uriarte D, Gamero E, Talaverano I and Vilanova M, Early leaf removal applied in warm climatic conditions: impact on Tempranillo wine volatiles. Food Res Int 98:50-58 (2017).

24. Vilanova M, Diago MP, Genisheva Z, Oliveira JM and Tardaguila J, Early leaf removal impact on volatile composition of Tempranillo wines. J Sci Food Agric 92:935-942 (2012).

25. Coetzee C and du Toit WJ, A comprehensive review on Sauvignon blanc aroma with a focus on certain positive volatile thiols. Food Res Int 45:287-298 (2012). 
26. Tominaga $\mathrm{T}$, Murat ML and Dubourdieu D, Development of a method for analyzing the volatile thiols involved in the characteristic aroma of wines made from Vitis vinifera L. cv. Sauvignon blanc. J Agric Food Chem 46:1044-1048 (1998).

27. Maletić E, Pejić I, Karoglan Kontić J, Zdunić G, Preiner D, Šimon S, Andabaka Ž, Žulj Mihaljević M, Bubola M, Marković Z, Stupić D and Mucalo A, Ampelographic and genetic characterization of Croatian grapevine varieties. Vitis, 54(SI):93-98 (2015).

28. Food and Agriculture Organization of the United Nations, Soil Map of the World, Volume V, Europe. Unesco, Paris, France, pp 70-71 (1981).

29. Coombe BG, Growth stages of the grapevine: the adoption of a system for identifying grapevine growth stages. Aust J Grape Wine Res 1:104-110 (1995)

30. Smart R and Robinson M, Sunlight into wine: A handbook for winegrape canopy management. Winetitles, Ashford, Australia, pp. 21-25. (1991).

31. European and Mediterranean Plant Protection Organization, Guidelines for the efficacy evaluation of fungicides. Botryotinia fuckeliana on grapevine. Bulletin ОЕРP/EPРО 31:299-302 (2001).

32. International Organisation of Vine and Wine, Compendium of international methods of wine and musts analysis. Paris, France, (2014).

33. Vanzo A, Janeš L, Požgan F, Velikonja Bolta Š, Sivilotti P and Lisjak K, UHPLCMS/MS determination of varietal thiol precursors in Sauvignon Blanc grapes. Sci Rep 7:13122 (2017).

34. Šuklje K, Baša Česnik H, Janeš L, Kmecl V, Vanzo A, Deloire A, Sivilotti P and Lisjak K, The effect of leaf area to yield ratio on secondary metabolites in grapes 
and wines of Vitis vinifera L. cv. Sauvignon blanc. J Int Sci Vigne Vin, 47:83-97 (2013).

35. Noguerol-Pato R, González-Barreiro C, Cancho-Grande B and Simal-Gándara J, Quantitative determination and characterisation of the main odourants of Mencía monovarietal red wines. Food Chem 117:473-484 (2009).

36. Vanzo A, Cecotti R, Vrhovsek U, Torres AM, Mattivi F and Passamonti S, The fate of trans-caftaric acid administered into the rat stomach. J Agric Food Chem 55:1604-1611 (2007).

37. Šuklje K, Lisjak K, Baša Česnik H, Janeš L, Du Toit W, Coetzee Z, Vanzo A and Deloire A, Classification of grape berries according to diameter and total soluble solids to study the effect of light and temperature on methoxypyrazine, glutathione, and hydroxycinnamate evolution during ripening of Sauvignon blanc (Vitis vinifera L.). J Agric Food Chem 60:9454-9461 (2012).

38. Feng H, Yuan F, Skinkis PA and Qian MC, Influence of cluster zone leaf removal on Pinot noir grape chemical and volatile composition. Food Chem 173:414-423 (2015).

39. Crippen DD and Morrison JC, The effects of sun exposure on the compositional development of Cabernet Sauvignon berries. Am J Enol Vitic 37:235-242 (1986).

40. Reynolds AG, Pool RM and Mattick LR, Influence of cluster exposure on fruit composition and wine quality of Seyval blanc grapes. Vitis, 25:85-95 (1986).

41. Maletić E, Karoglan Kontić J, Pejić I, Preiner D, Zdunić G, Bubola M, Stupić D, Andabaka Ž, Marković Z, Šimon S, Žulj Mihaljević M, Ilijaš, I and Marković D, Green Book: Indigenous Grapevine Varieties of Croatia. State Institute for Nature Protection. Zagreb, Croatia, pp. 312-313 (2015). 
42. Kliewer WM and Dokoozlian NK, Leaf area/crop weight ratios of grapevines: Influence on fruit composition and wine quality. Am J Enol Vitic 56:170-181 (2005).

43. Sivilotti P, Falchi R, Herrera JC, Škvarč B, Butinar L, Sternad Lemut M, Bubola M, Sabbatini P, Lisjak K and Vanzo A, Combined effects of early season leaf removal and climatic conditions on aroma precursors in Sauvignon blanc grapes. $J$ Agric Food Chem 65:8426-8434 (2017).

44. Kobayashi H, Takase H, Suzukim Y, Tanzawa F, Takata R, Fujita K, Kohno M, Mochizuki M, Suzuki S and Konno T, Environmental stress enhances biosynthesis of flavor precursors, S-3-(hexan-1-ol)-glutathione and S-3-(hexan-1-ol)-L-cysteine, in grapevine through glutathione S-transferase activation. J Exp Bot 62:1325-1336 (2011).

45. Sarrazin E, Shinkaruk S, Tominaga T, Bennetau B, Frérot E and Dubourdieu D, Odorous impact of volatile thiols on the aroma of young botrytized sweet wines: Identification and quantification of new sulfanyl alcohols. J Agric Food Chem 55:1437-1444 (2007).

46. Gil M, Bottini R, Berli F, Pontin M, Silva MF and Piccoli P, Volatile organic compounds characterized from grapevine (Vitis vinifera L. cv. Malbec) berries increase at pre-harvest and in response to UV-B radiation. Phytochemistry, 96:148157 (2013).

47. Matus JT, Transcriptomic and metabolomic networks in the grape berry illustrate that it takes more than flavonoids to fight against ultraviolet radiation. Front Plant Sci 7:1337 (2016). 
48. González-Barreiro C, Rial-Otero R, Cancho-Grande B and Simal-Gándara J, Wine aroma compounds in grapes: a critical review. Crit Rev Food Sci 55:202-218 (2015).

49. Bavaresco L, Gatti M, Pezzutto S, Fregoni M and Mattivi F, Effect of leaf removal on grape yield, berry composition, and stilbene concentration. Am J Enol Vitic 59:292-298 (2008).

50. Guth H, Quantitation and sensory studies of character impact odorants of different white wine varieties. J Agric Food Chem 45:3027-3032 (1997).

51. Ferreira V, López R and Cacho JF, Quantitative determination of the odorants of young red wines from different grape varieties. J Sci Food Agric 80:1659-1667 (2000).

52. Benkwitz F, Nicolau L, Lund S, Beresford M, Wohlers M and Kilmartin PA, Evaluation of key odorants in Sauvignon blanc wines using three different methodologies. J Agric Food Chem 60:6293-6302 (2012).

53. Ribereau-Gayon P, Boidron JN and Terrier A, Aroma of Muscat grape varieties. $J$ Agric Food Chem 23:1042-1047 (1975). 


\section{TABLES}

\section{Table 1}

Canopy characteristics determined on Istrian Malvasia vines subjected to hand and mechanical leaf removal.

\begin{tabular}{|c|c|c|c|c|}
\hline & $\mathrm{UC}$ & MLR & HLR & Significance $^{a}$ \\
\hline \multicolumn{5}{|l|}{ Fruit zone characteristics upon leaf removal $^{b}$} \\
\hline Canopy gaps in the fruit zone $(\%)$ & $5.0 \pm 1.8 \mathrm{c}^{c}$ & $23.4 \pm 4.0 \mathrm{~b}$ & $44.3 \pm 5.1 \mathrm{a}$ & $* * *$ \\
\hline $\mathrm{LLN}^{d}$ in the fruit zone & $2.03 \pm 0.20 \mathrm{a}$ & $1.27 \pm 0.13 b$ & $0.74 \pm 0.09 \mathrm{c}$ & $* * *$ \\
\hline \multicolumn{5}{|l|}{ Fruit zone characteristics at harvest $t^{e}$} \\
\hline Canopy gaps in the fruit zone $(\%)$ & $2.2 \pm 0.7 \mathrm{c}$ & $8.3 \pm 1.7 b$ & $19.1 \pm 3.3 \mathrm{a}$ & $* * *$ \\
\hline LLN in the fruit zone & $2.41 \pm 0.20 \mathrm{a}$ & $1.82 \pm 0.11 b$ & $1.17 \pm 0.14 \mathrm{c}$ & $* * *$ \\
\hline \multicolumn{5}{|l|}{$\mathrm{PAR}^{f}$ in the fruit zone } \\
\hline PAR $\left(\mu \mathrm{mol} \mathrm{m} \mathrm{m}^{-2} \mathrm{~s}^{-1}\right)$ & $39 \pm 13 c$ & $84 \pm 22 b$ & $172 \pm 35 a$ & $* * *$ \\
\hline$\%$ ambient PAR measured & $3.2 \pm 1.0 \mathrm{c}$ & $7.1 \pm 1.7 b$ & $13.8 \pm 2.8 \mathrm{a}$ & $* * *$ \\
\hline \multicolumn{5}{|l|}{ Vine leaf area ${ }^{e}$} \\
\hline Primary shoot leaf area per vine $\left(\mathrm{m}^{2}\right)$ & $1.67 \pm 0.22 \mathrm{a}$ & $1.23 \pm 0.11 b$ & $0.96 \pm 0.16 c$ & $* *$ \\
\hline Lateral shoot leaf area per vine $\left(\mathrm{m}^{2}\right)$ & $1.71 \pm 0.21$ & $1.85 \pm 0.28$ & $1.79 \pm 0.17$ & NS \\
\hline Total leaf area per vine $\left(\mathrm{m}^{2}\right)$ & $3.37 \pm 0.18 \mathrm{a}$ & $3.08 \pm 0.33 \mathrm{ab}$ & $2.75 \pm 0.29 b$ & $*$ \\
\hline
\end{tabular}




\section{Table 2}

Yield components and Botrytis cinerea incidence and severity determined on Istrian Malvasia vines subjected to hand and mechanical leaf removal

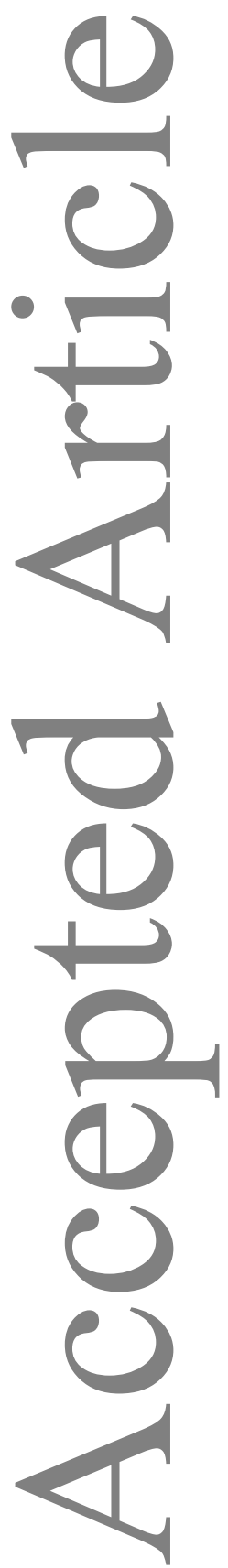

\begin{tabular}{|c|c|c|c|c|}
\hline & $\mathrm{UC}$ & MLR & HLR & Significance $^{a}$ \\
\hline \multicolumn{5}{|l|}{ Yield components } \\
\hline Yield per vine (kg) & $2.33 \pm 0.28$ & $2.31 \pm 0.20$ & $2.19 \pm 0.30$ & NS \\
\hline Clusters per vine & $13.7 \pm 1.0$ & $13.5 \pm 1.3$ & $13.4 \pm 1.0$ & NS \\
\hline Cluster weight (g) & $169 \pm 11$ & $171 \pm 7$ & $162 \pm 10$ & NS \\
\hline Shoots per vine & $9.4 \pm 0.5$ & $9.0 \pm 0.8$ & $9.2 \pm 0.5$ & NS \\
\hline Clusters per shoot & $1.47 \pm 0.12$ & $1.50 \pm 0.09$ & $1.46 \pm 0.17$ & NS \\
\hline Berry weight (g) & $2.65 \pm 0.07 \mathrm{a}$ & $2.60 \pm 0.08 \mathrm{ab}$ & $2.53 \pm 0.07 b$ & * \\
\hline Berries per cluster & $64 \pm 5$ & $66 \pm 3$ & $64 \pm 6$ & NS \\
\hline Leaf area/yield $\left(\mathrm{m} \mathrm{kg}^{-1}\right)$ & $1.46 \pm 0.15$ & $1.34 \pm 0.19$ & $1.27 \pm 0.21$ & NS \\
\hline \multicolumn{5}{|l|}{ Botrytis cinerea rot on clusters } \\
\hline Incidence & $23 \pm 6 a$ & $11 \pm 7 b$ & $5 \pm 4 b$ & $*$ \\
\hline Severity & $16 \pm 4 \mathrm{a}$ & $10 \pm 4 a b$ & $6 \pm 3 b$ & $*$ \\
\hline
\end{tabular}

${ }^{a}$ Data were analyzed by one-way ANOVA (NS, not significant; *, $p \leq 0.05 ;{ }^{* *}, p \leq 0.01 ; * * *, p \leq 0.001$ ) and when differences were significant, mean separation was performed with Fisher's LSD test $(p \leq 0.05) .{ }^{b}$ Different letters identify significantly different means. UC, untreated control; MLR, mechanical leaf removal; HLR, hand leaf removal. 


\section{Table 3}

Basic composition of Istrian Malvasia grape juice and wine produced from different leaf removal treatments.

\begin{tabular}{|c|c|c|c|c|}
\hline & $\mathrm{UC}$ & MLR & HLR & Significance $^{a}$ \\
\hline \multicolumn{5}{|l|}{ Grape juice } \\
\hline Brix & $19.1 \pm 0.5 b^{b}$ & $20.2 \pm 0.7 \mathrm{a}$ & $20.3 \pm 0.4 \mathrm{a}$ & * \\
\hline Titratable acidity $\left(\mathrm{g} \mathrm{L}^{-1}\right)$ & $8.2 \pm 0.3 \mathrm{a}$ & $7.5 \pm 0.4 b$ & $7.3 \pm 0.2 b$ & * \\
\hline $\mathrm{pH}$ & $3.20 \pm 0.03$ & $3.23 \pm 0.03$ & $3.25 \pm 0.02$ & NS \\
\hline \multicolumn{5}{|l|}{ Wine } \\
\hline Alcohol (vol \%) & $11.4 \pm 0.3 b$ & $11.9 \pm 0.4 \mathrm{a}$ & $12.0 \pm 0.2 \mathrm{a}$ & $*$ \\
\hline Titratable acidity $\left(\mathrm{g} \mathrm{L}^{-1}\right)$ & $7.5 \pm 0.3 \mathrm{a}$ & $7.1 \pm 0.2 \mathrm{ab}$ & $6.8 \pm 0.2 b$ & $*$ \\
\hline $\mathrm{pH}$ & $3.15 \pm 0.07$ & $3.18 \pm 0.04$ & $3.21 \pm 0.05$ & NS \\
\hline Total extract $\left(\mathrm{g} \mathrm{L}^{-1}\right)$ & $22.2 \pm 0.3$ & $22.0 \pm 0.5$ & $21.9 \pm 0.2$ & NS \\
\hline Residual sugar $\left(\mathrm{g} \mathrm{L}^{-1}\right)$ & $1.5 \pm 0.1$ & $1.5 \pm 0.1$ & $1.6 \pm 0.1$ & NS \\
\hline Dry extract $\left(\mathrm{g} \mathrm{L}^{-1}\right)$ & $20.7 \pm 0.3$ & $20.5 \pm 0.5$ & $20.4 \pm 0.2$ & NS \\
\hline Ash $\left(\mathrm{g} \mathrm{L}^{-1}\right)$ & $2.34 \pm 0.19$ & $2.34 \pm 0.19$ & $2.26 \pm 0.11$ & NS \\
\hline
\end{tabular}

${ }^{a}$ Data were analyzed by one-way ANOVA (NS, not significant; *, $p \leq 0.05 ;{ }^{* *}, p \leq 0.01 ; * * *, p \leq 0.001$ ) and when differences were significant, mean separation was performed with Fisher's LSD test $(p \leq 0.05) .{ }^{b}$ Different letters identify significantly different means. UC, untreated control; MLR, mechanical leaf removal; HLR, hand leaf removal. 


\section{Table 4}

Concentrations of precursors of varietal thiols in Istrian Malvasia grape berries from different leaf removal treatments.

\begin{tabular}{lcccc}
\hline & $\mathrm{UC}$ & $\mathrm{MLR}$ & $\mathrm{HLR}$ & \multicolumn{2}{c}{ Significance $^{a}$} \\
\hline 4-S-cysteinyl-4-methylpentan-2-one $\left(\mathrm{ng} \mathrm{kg}^{-1}\right)$ & $22.4 \pm 2.2$ & $27.0 \pm 2.0$ & $28.5 \pm 7.7$ & $\mathrm{NS}$ \\
4-S-glutathionyl-4-methylpentan-2-one $\left(\mathrm{ng} \mathrm{kg}^{-1}\right)$ & $11.8 \pm 3.2$ & $17.6 \pm 9.5$ & $16.4 \pm 9.3$ & $\mathrm{NS}$ \\
3-S-cysteinylhexan-1-ol $\left(\mu \mathrm{g} \mathrm{kg}^{-1}\right)$ & $0.3 \pm 0.1$ & $0.6 \pm 0.3$ & $0.5 \pm 0.1$ & $\mathrm{NS}$ \\
$3-S$-glutathionylhexan-1-ol $\left(\mu \mathrm{g} \mathrm{kg}^{-1}\right)$ & $7.0 \pm 2.3$ & $10.6 \pm 1.8$ & $9.5 \pm 1.6$ & $\mathrm{NS}$ \\
\hline
\end{tabular}

${ }^{a}$ Data were analyzed by one-way ANOVA (NS, not significant). UC, untreated control; MLR, mechanical leaf removal; HLR, hand leaf removal. 


\section{Table 5}

Concentrations of aroma compounds and hydroxycinnamates in Istrian Malvasia wine produced from different leaf removal treatments.

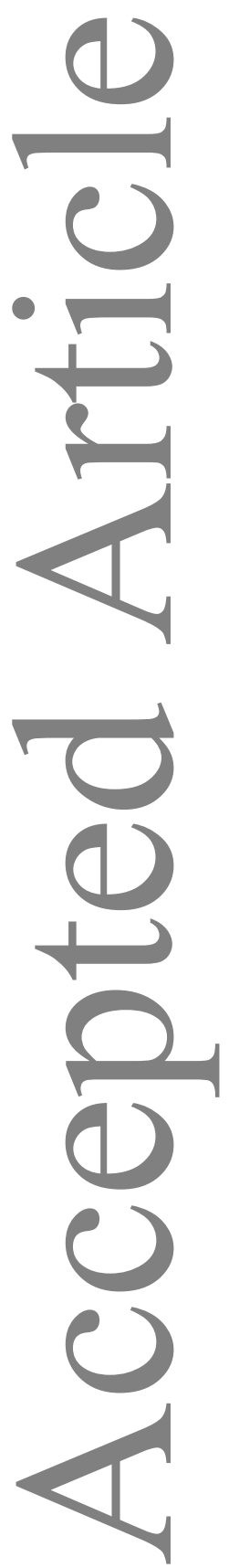

\begin{tabular}{|c|c|c|c|c|}
\hline & UC & MLR & HLR & Significance $^{a}$ \\
\hline \multicolumn{5}{|l|}{ Varietal thiols } \\
\hline 4-methyl-4-sulfanylpentan-2-one $\left(\mathrm{ng} \mathrm{L}^{-1}\right)$ & $7.9 \pm 1.8 \mathrm{a}^{b}$ & $5.6 \pm 0.4 b$ & $4.9 \pm 0.5 b$ & $*$ \\
\hline 3-sulfanylhexan-1-ol (ng L $\left.{ }^{-1}\right)$ & $306 \pm 58 b$ & $387 \pm 60 \mathrm{a}$ & $411 \pm 38 \mathrm{a}$ & $*$ \\
\hline 3-sulfanylhexyl acetate $\left(\mathrm{ng} \mathrm{L}^{-1}\right)$ & $\mathrm{ND}^{c}$ & ND & ND & - \\
\hline \multicolumn{5}{|l|}{ Monoterpenes } \\
\hline Linalool $\left(\mu \mathrm{g} \mathrm{L}^{-1}\right)$ & $9.8 \pm 0.6 b$ & $10.3 \pm 0.7 b$ & $11.9 \pm 0.3 \mathrm{a}$ & $* *$ \\
\hline$\alpha$-terpineol $\left(\mu \mathrm{g} \mathrm{L}^{-1}\right)$ & $4.2 \pm 0.9$ & $4.3 \pm 0.3$ & $4.5 \pm 1.1$ & NS \\
\hline Citronellol $\left(\mu \mathrm{g} \mathrm{L}^{-1}\right)$ & $5.0 \pm 0.7 b$ & $8.8 \pm 0.8 \mathrm{a}$ & $4.9 \pm 0.9 b$ & $* * *$ \\
\hline $\operatorname{Nerol}\left(\mu \mathrm{g} \mathrm{L}^{-1}\right)$ & $1.0 \pm 0.2 b$ & $2.3 \pm 0.5 \mathrm{a}$ & $2.3 \pm 0.6 \mathrm{a}$ & $*$ \\
\hline Geraniol $\left(\mu \mathrm{g} \mathrm{L}^{-1}\right)$ & $8.9 \pm 1.0 \mathrm{~b}$ & $12.7 \pm 0.7 \mathrm{a}$ & $11.2 \pm 1.7 \mathrm{a}$ & $*$ \\
\hline \multicolumn{5}{|l|}{ C13-norisoprenoid } \\
\hline$\beta$-damascenone $\left(\mu \mathrm{g} \mathrm{L}^{-1}\right)$ & $1.5 \pm 0.2 b$ & $2.4 \pm 0.6 \mathrm{a}$ & $2.4 \pm 0.5 \mathrm{a}$ & $*$ \\
\hline \multicolumn{5}{|l|}{ Alcohols } \\
\hline 1-hexanol $\left(\mu \mathrm{g} \mathrm{L}^{-1}\right)$ & $910.5 \pm 44.4$ & $980.3 \pm 125.4$ & $963.6 \pm 25.9$ & NS \\
\hline 2-phenylethyl alcohol $\left(\mathrm{mg} \mathrm{L}^{-1}\right)$ & $15.1 \pm 2.0$ & $17.2 \pm 0.8$ & $18.4 \pm 2.0$ & NS \\
\hline \multicolumn{5}{|l|}{ Ethyl esters } \\
\hline Ethyl isobutyrate $\left(\mu \mathrm{g} \mathrm{L}^{-1}\right)$ & $26.6 \pm 3.3$ & $30.9 \pm 2.7$ & $30.6 \pm 4.2$ & NS \\
\hline Ethyl butyrate $\left(\mu \mathrm{g} \mathrm{L}^{-1}\right)$ & $191.0 \pm 23.9 b$ & $226.2 \pm 27.6 b$ & $281.1 \pm 23.8 \mathrm{a}$ & $*$ \\
\hline Ethyl 2-methylbutyrate $\left(\mu \mathrm{g} \mathrm{L}^{-1}\right)$ & $4.4 \pm 0.3 \mathrm{c}$ & $5.5 \pm 0.3 b$ & $6.2 \pm 0.6 \mathrm{a}$ & $* *$ \\
\hline Ethyl 3-methylbutyrate $\left(\mu \mathrm{g} \mathrm{L}^{-1}\right)$ & $12.9 \pm 1.0 \mathrm{~b}$ & $14.9 \pm 1.6 \mathrm{ab}$ & $16.9 \pm 2.0 \mathrm{a}$ & $*$ \\
\hline Ethyl hexanoate $\left(\mu \mathrm{g} \mathrm{L}^{-1}\right)$ & $208.5 \pm 28.3 b$ & $284.2 \pm 30.4 \mathrm{a}$ & $303.2 \pm 25.7 a$ & $* * *$ \\
\hline Ethyl octanoate $\left(\mu \mathrm{g} \mathrm{L}^{-1}\right)$ & $80.7 \pm 18.9 b$ & $120.8 \pm 15.9 \mathrm{a}$ & $115.9 \pm 12.6 \mathrm{a}$ & $*$ \\
\hline \multicolumn{5}{|l|}{ Acetate esters } \\
\hline Isobutyl acetate $\left(\mu \mathrm{g} \mathrm{L}^{-1}\right)$ & $18.6 \pm 2.1 b$ & $29.5 \pm 4.2 \mathrm{a}$ & $29.2 \pm 4.1 \mathrm{a}$ & $* * *$ \\
\hline Isoamyl acetate $\left(\mu \mathrm{g} \mathrm{L}^{-1}\right)$ & $816.4 \pm 91.4 b$ & $1060.9 \pm 151.1 \mathrm{a}$ & $1024.0 \pm 144.1 \mathrm{a}$ & $*$ \\
\hline 2-phenylethyl acetate $\left(\mu \mathrm{g} \mathrm{L}^{-1}\right)$ & $915.6 \pm 134.5$ & $1048.6 \pm 194.7$ & $1053.1 \pm 138.1$ & NS \\
\hline \multicolumn{5}{|l|}{ Fatty acids } \\
\hline Hexanoic acid $\left(\mathrm{mg} \mathrm{L}^{-1}\right)$ & $3.5 \pm 0.2 b$ & $4.5 \pm 0.5 \mathrm{a}$ & $4.2 \pm 0.3 a$ & $* *$ \\
\hline Octanoic acid $\left(\mathrm{mg} \mathrm{L}^{-1}\right)$ & $4.8 \pm 0.6$ & $5.2 \pm 0.5$ & $5.6 \pm 0.7$ & NS \\
\hline Decanoic acid $\left(\mathrm{mg} \mathrm{L}^{-1}\right)$ & $1.3 \pm 0.6$ & $1.4 \pm 0.5$ & $1.6 \pm 0.3$ & NS \\
\hline \multicolumn{5}{|l|}{ Hydroxycinnamates } \\
\hline cis-caftaric acid $\left(\mathrm{mg} \mathrm{L}^{-1}\right)$ & $0.6 \pm 0.1 b^{b}$ & $0.8 \pm 0.2 \mathrm{ab}$ & $0.9 \pm 0.3 \mathrm{a}$ & $*$ \\
\hline trans-caftaric acid $\left(\mathrm{mg} \mathrm{L}^{-1}\right)$ & $14.1 \pm 2.3 b$ & $16.1 \pm 4.6 b$ & $21.6 \pm 3.9 \mathrm{a}$ & $*$ \\
\hline cis-coutaric acid $\left(\mathrm{mg} \mathrm{L}^{-1}\right)$ & $1.2 \pm 0.3$ & $1.1 \pm 0.2$ & $1.3 \pm 0.1$ & NS \\
\hline trans-coutaric acid $\left(\mathrm{mg} \mathrm{L}^{-1}\right)$ & $1.5 \pm 0.3$ & $1.5 \pm 0.5$ & $1.6 \pm 0.3$ & NS \\
\hline$c i s$-fertaric acid $\left(\mathrm{mg} \mathrm{L}^{-1}\right)$ & $0.2 \pm 0.1$ & $0.1 \pm 0.1$ & $0.2 \pm 0.1$ & NS \\
\hline trans-fertaric acid $\left(\mathrm{mg} \mathrm{L}^{-1}\right)$ & $2.4 \pm 0.2 b$ & $2.6 \pm 0.2 b$ & $2.9 \pm 0.1 \mathrm{a}$ & $* *$ \\
\hline Caffeic acid $\left(\mathrm{mg} \mathrm{L}^{-1}\right)$ & $17.7 \pm 1.7$ & $18.2 \pm 2.2$ & $21.3 \pm 3.2$ & NS \\
\hline$p$-coumaric acid $\left(\mathrm{mg} \mathrm{L}^{-1}\right)$ & $4.5 \pm 0.4 b$ & $5.0 \pm 0.4 a$ & $4.8 \pm 0.3 \mathrm{ab}$ & $*$ \\
\hline Ferulic acid $\left(\mathrm{mg} \mathrm{L}^{-1}\right)$ & $2.4 \pm 0.3$ & $2.6 \pm 0.3$ & $2.4 \pm 0.2$ & NS \\
\hline 2-S-glutathionyl caftaric acid $\left(\mathrm{mg} \mathrm{L}^{-1}\right)$ & $5.7 \pm 1.2$ & $5.8 \pm 0.6$ & $6.2 \pm 0.4$ & NS \\
\hline Total hydroxycinnamates ${ }^{d}\left(\mathrm{mg} \mathrm{L}^{-1}\right)$ & $50.2 \pm 3.8 b$ & $53.7 \pm 5.5 b$ & $63.3 \pm 3.5 \mathrm{a}$ & $*$ \\
\hline
\end{tabular}

${ }^{a}$ Data were analyzed by one-way ANOVA (NS, not significant; * $\left.p \leq 0.05 ; * *, p \leq 0.01 ; * *, p \leq 0.001\right)$ and when differences were significant, mean separation was performed with Fisher's LSD test $(p \leq 0.05)$. ${ }^{b}$ Different letters identify significantly different means. UC, untreated control; MLR, mechanical leaf removal; HLR, hand leaf removal. ${ }^{c}$ Not detected. ${ }^{d}$ The concentration of 2-Sglutathionyl caftaric acid (grape reaction product) is included in total hydroxycinnamates. 


\section{FIGURES}

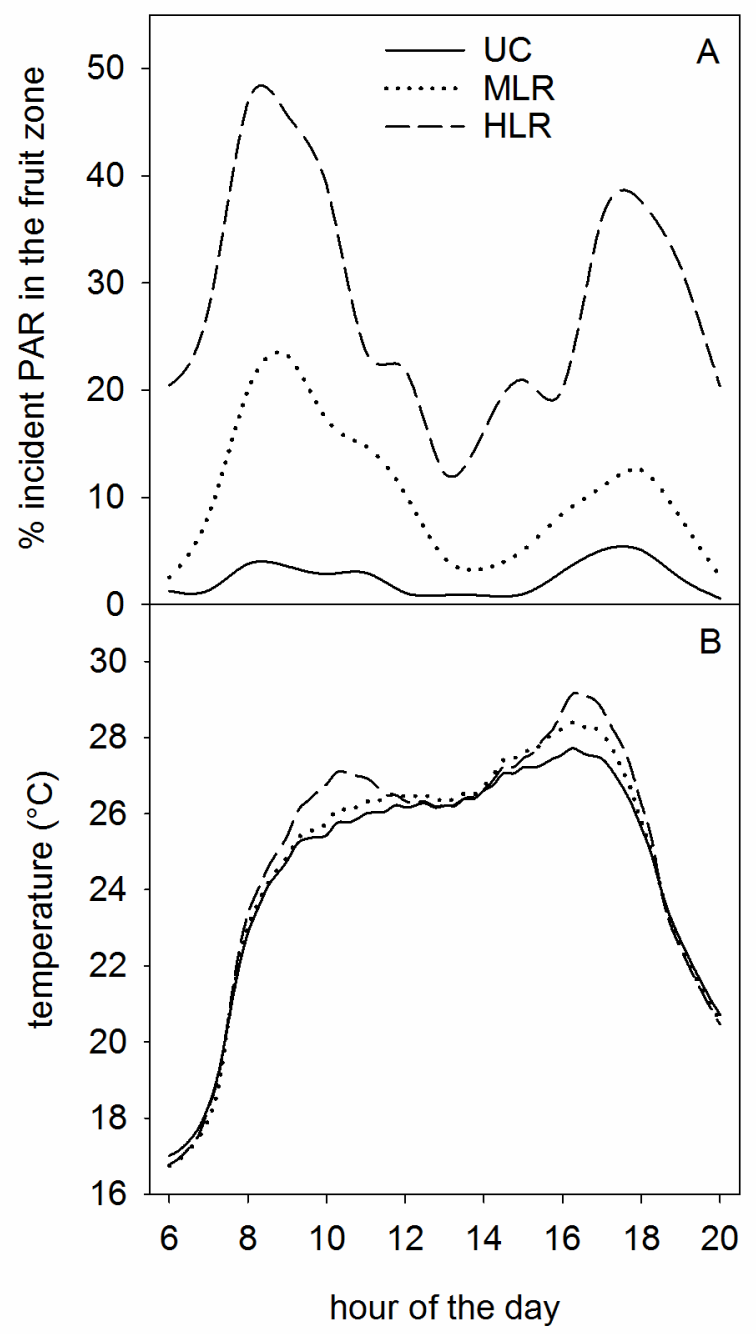

Fig. 1. Effect of leaf removal on A) \% incident photosynthetic active radiation (PAR) in fruit zone and B) cluster temperature of Istrian Malvasia vines, measured during the period from leaf removal date to harvest. UC, untreated control; MLR, mechanical leaf removal; HLR, hand leaf removal. 


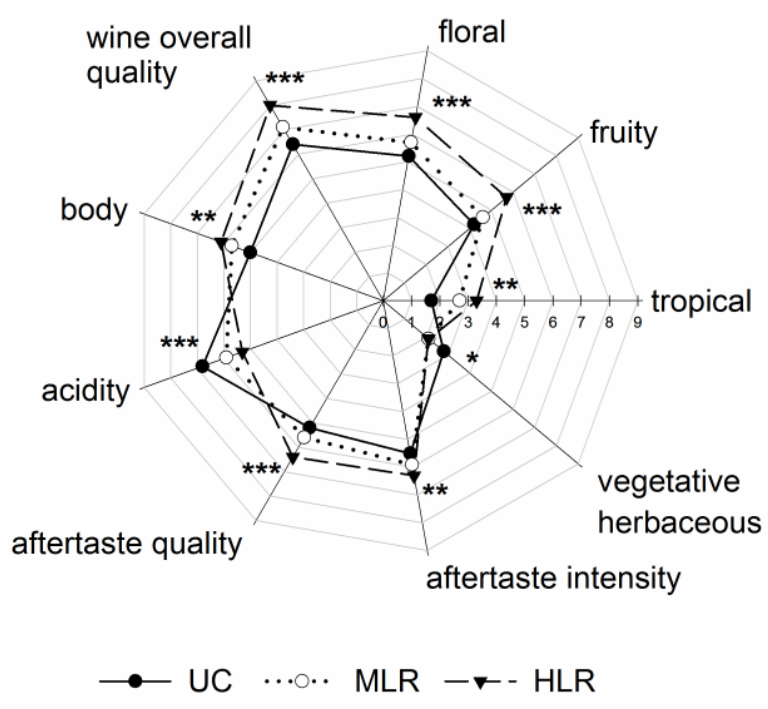

Fig. 2. Sensory characteristics of Istrian Malvasia wines produced from leaf removal treatments. Data were analyzed by one-way ANOVA (ns, not significant; ${ }^{*}, p \leq 0.05$; $\left.*^{*}, p \leq 0.01 ; * * *, p \leq 0.001\right)$. Differences between treatments are reported in Supporting Information, Table S3. UC, untreated control; MLR, mechanical leaf removal; HLR, hand leaf removal. 